\title{
Outcome of Percutaneous Nephrolithotomy in Horseshoe Kidneys
}

\author{
Udaya Man Singh Dongol, a,c Sandeep Bohorab,d
}

\begin{abstract}
:
Introduction: The horseshoe kidney is extremely rare, the incidence being one in every 400 - 800 patients. In a recent review of more than 15000 radiographic imaging studies, the incidence was one in every 666 patients. The renal stone formation in horseshoe kidney is around 20-80\%. Percutaneous nephrolithotomy is the most accepted modality of treatment . This study was carried out to find the outcome of percutaneous nephrolithotomy in horseshoe kidneys. Methods: Between May 2013 and November 2017, 11 adult patients(12 renal units) with stones in horseshoe kidneys underwent percutaneous nephrolithotomy in the department of urosurgery, Kathmandu Medical College and Teaching Hospital and were evaluated for the operating time, stone free rate , complications and hospital stay. Data analysis was done using Statistical Package for the Social sciences (SPSS) Version 20. Categorical data were analysed by using Fisher exact test. Results: The mean age of the patients was 30.9 years (SD $=10.3)$ and the mean stone burden was $385.83 \mathrm{~mm}^{2} \quad(\mathrm{SD}=331.3)$. The overall stone free rate was 83.33\%. The two patients with residual stones when counselled for Extracorporeal shock wave lithotripsy, refused for it and decided to be on follow up. No auxiliary procedure was done. The complications noted were of Clavien-Dindo grade I and II. No pleural or bowel injury was seen. One patient needed blood transfusion. Conclusions: Percutaneous nephrolithotomy is safe and effective in the management of stones in horseshoe kidneys. It does not carry increased risk than reported in normal kidneys.
\end{abstract}

Keywords: horseshoe kidney, percutaneous nephrolithotomy, renal stones

Submitted: 10 April 2018

Accepted: 01 August 2018

Published: 16 August 2018

a - Associate Professor

b - Junior Resident

c - Department of Urosurgery, Kathmandu Medical College, Nepal

d - Department of Surgery, Kathmandu Medical College, Nepal

Corresponding Author:

Udaya Man Singh Dongol

e-mail: dongoludaya@gmail.com

ORCID: https://orcid.org/0000-0002-8793-8717

How to cite this article:

Dongol UMS, Bohora S. Outcome of percutaneous nephrolithotomy in horseshoe kidneys. Journal of Lumbini Medical College. 2018;6(2):6 pages. DOI: 10.22502/jlmc.v6i2.238. Epub: 2018 August 16.

\section{(c) (1)}

Licensed under CC BY 4.0 International License which permits use, distribution and reproduction in any medium, provided the original work is properly cited.

\section{INTRODUCTION:}

In genitourinary tract, the incidence of developmental anomalies is about 30 - 40\%. [1] Fusion anomalies of kidneys are common and are predisposed to various complications of nephrolithiasis, hydronephrosis, infection and possibility of renal malignancy.[2] Horseshoe kidney is the most common renal fusion anomaly with the incidence of one in 400 - 800 cases and male to female ratio of 2:1.[3] In a recent review of radiographic imaging studies, the incidence of horseshoe kidney has been found to be one in 400 - 600 individuals with fusion at the lower poles in greater than $90 \%$ of the cases, with the rest showing fusion at the upper poles.[4] The fusion of the lower poles which occurs at $4^{\text {th }}-6^{\text {th }}$ week of gestation, prevents the normal ascent of kidneys when it reaches the inferior mesenteric artery. There is malrotation of the kidney with anterior displacement of the collecting system and high lateral insertion of ureters. The significant ureteropelvic obstruction due to high lateral insertion of ureters is associated with 
impaired drainage of the collecting system, urinary infection and stone formation.[5,6] The incidence of renal stones in adult patients with horseshoe kidneys is estimated to be 36\%.[7] The prevalence of complex staghorn calculus in horseshoe kidney is however rare.[8] The commonest presentation is the flank pain and is seen in $83 \%$ of population with horseshoe kidneys.[9]

Although the treatment of nephrolithiasis in horseshoe kidneys is challenging due to anomalies in position of the kidney, the anatomy of pelvic collecting system and vascular supply, percutaneous nephrolithotomy has been accepted as the treatment of choice for stones more than $2 \mathrm{~cm}$.[10,11,12] The dorsomedial orientation of posterior calyces and dorsolateral orientation of anterior calyces offer surprisingly the good percutaneous access. The stone clearance rate of percutaneous nephrolithotomy in horseshoe kidneys varies and ranges from $75 \%$ to $100 \%$ with an average stone-free rate of $84 \%$.[13] The first report of percutaneous nephrolithotomy in horseshoe kidney was made by Wickkam and Kellet in 1981 and by Clayman in 1983.[14]

The anatomic and vascular anomalies in horseshoe kidneys increase the technical complexity and makes the management of stone in horseshoe kidneys by percutaneous nephrolithotomy challenging, despite the higher stone free rate with minimal major complications. This study was carried out to find the outcome of percutaneous nephrolithotomy in horseshoe kidneys in our set up.

\section{METHODS:}

It was an observational study and data were collected prospectively. The study was done from May 2013 up to November 2017. Approval from the ethical committee was taken and informed consent was taken from all the patients.

All adult patients with stone(s) in horseshoe kidneys who underwent percutaneous nephrolithotomy in the department of urosurgery in Kathmandu Medical College and Teaching Hospital during the study period were included in the study. The evaluation of all patients was done with a detailed medical history and physical examination, complete blood count, urinalysis, urine culture and sensitivity, coagulation tests, renal function tests. All the patients also underwent comprehensive radiological assessment including X-ray KUB, intravenous urography, ultrasonography of abdomen and pelvis. It was only from 2015 that we started doing computed tomographic urography in our patients (six cases, seven renal units) (Fig 1). Patients with positive urine cultures were treated with appropriate antibiotics. The stone burden was calculated by measuring the digitized surface area (DSA) of stone on plain X-ray. For a stone of 10 $\mathrm{mm}$ by six mm dimensions, the DSA was $60 \mathrm{~mm}^{2}$ and for two stones of $10 \mathrm{~mm}$ by six $\mathrm{mm}$ and eight $\mathrm{mm}$ by five $\mathrm{mm}$, it was $60+40=100 \mathrm{~mm}^{2}$.

Percutaneous nephrolithotomy (PCNL) was performed in all patients in prone position under general anaesthesia with dilatation of the tracts up to $24 / 26$ Fr. A dose of prophylactic antibiotics was given with the induction of general anaesthesia. After cystoscopy and ureteral catheterization with six Fr ureteric catheter, the patient was kept in prone position and delineation of pelvicalyceal system was done with the contrast media. The desired calyx was punctured with $18 \mathrm{~g}$ angiographic needle. Due to the downward and medial displacement of the calyces, C-arm at 90 degree provides a direct end on view of the posterior calyx. After puncture of the calyx, C-arm was then rotated towards the surgeon

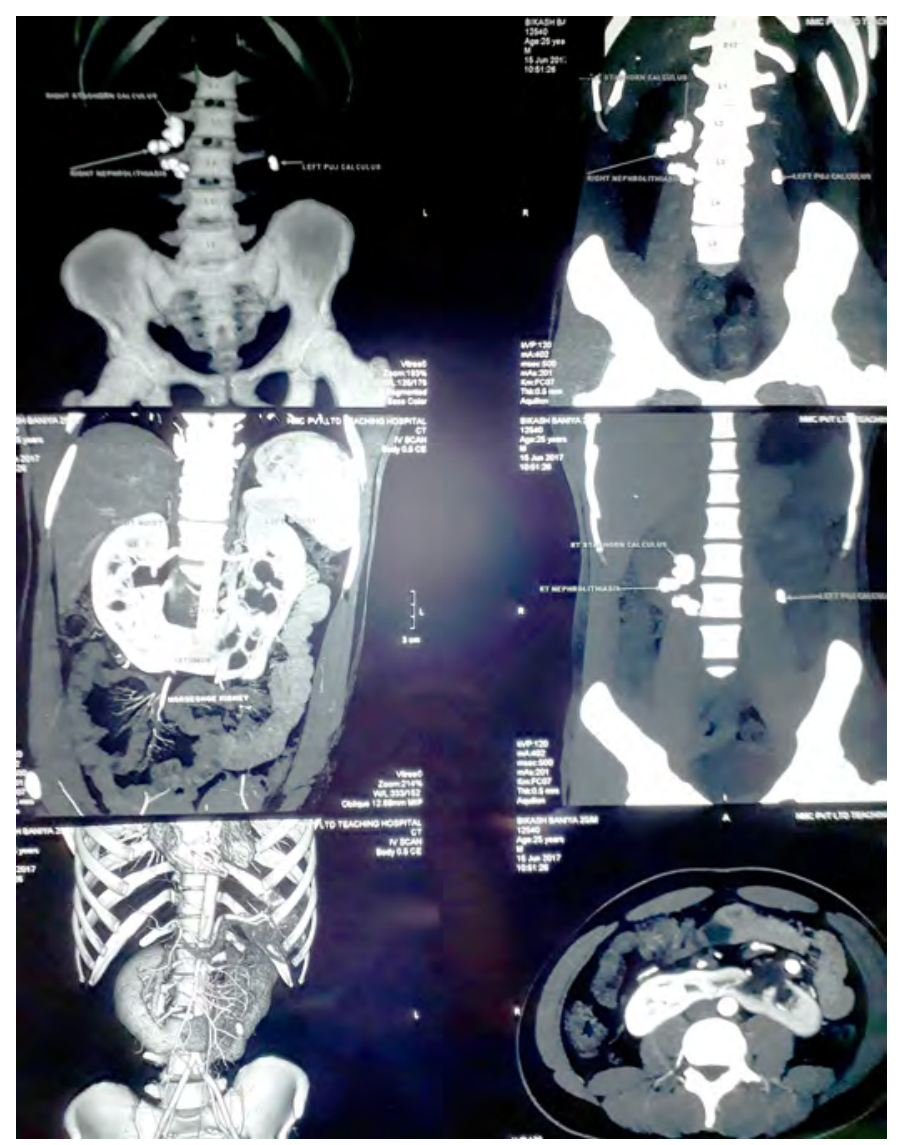

Fig 1: CT urography of a patient with horseshoe kidney with bilateral renal stones 
to see the depth of penetration of needle. The site of puncture was chosen depending upon the location and number of stones as well as the orientation of the calyces. In ten renal units, upper calyceal puncture was made and in the two remaining renal units, mid calyceal puncture was made. All the upper pole calyceal punctures were made infracostal due to low lying kidneys without any pleural injury.

Once puncture was confirmed, a 0.035 inch thick and $150 \mathrm{~cm}$ long Radifocus Terumo nitinol hydrophilic guide wire was passed into the collecting system and well parked into the ureter. Acute dilatation of the tract was done with the metallic coaxial dilators up to 24/26 Fr. Nephroscopy was done with 20 Fr rigid nephroscope (Richard Wolf). Once the stone was visualised, fragmentation was done with Nidhi Pneumatic Lithotripter and all the fragments were removed. An attempt was made to remove all the fragments as far as possible. DJ stenting was done and nephrostomy tube was placed in all cases at the end of the procedure. Nephrostomy tube was removed on third postoperative day and DJ stent in three weeks. X-ray KUB (Fig 2) and ultrasonography of abdomen and pelvis was done before removal of nephrostomy tube and at three weeks as well as at six weeks. Patients with stone fragments less than four mm were considered stone free.

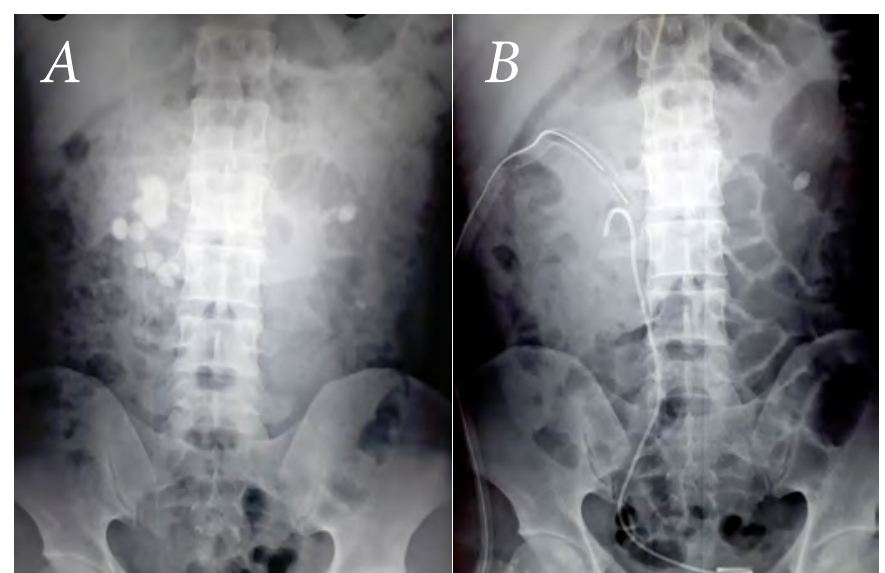

Fig 2: (A) X-ray Plain KUB showing stones in both horseshoe kidneys, (B) KUB of same patient after PCNL on right side

Descriptive data analysis was done using Statistical Package for the Social sciences (SPSS) Version 20. Descriptive results were presented as mean, standard deviation, frequency, and percentages. Categorical data were analysed by using Fisher exact test. $\mathrm{P}$ value less than 0.05 was considered significant.

\section{RESULTS:}

There were 11 patients and 12 renal units, one patient having bilateral renal stones. In six renal units, there was single renal stone, four in the pelvis and two in the lower calyx. In one patient with bilateral stones, there were multiple stones in different calyces including large staghorn calculus in the pelvis in one renal unit and a pelvic calculus in the other renal unit. There were two to three stones in the remaining four renal units in lower calyces including in the isthmus in one case. In seven cases, the stones were on right side, in three cases it was on left side and in one case it was on both sides. Demographic profile and perioperative variables of the patients is presented in Table 1.

Six patients $(54.5 \%)$ presented with flank pain, three (27.2\%) with haematuria and two (18\%) with dysuria. In almost all cases, horseshoe kidney was diagnosed in ultrasonography of abdomen. Intravenous urography was also done. In six cases (seven renal units) after 2015 AD, CT urography was done. In ten renal units, percutaneous access was made through upper pole calyx and in remaining two units, through the middle calyx. The mean operating time from puncture to placement of nephrostomy drain tube was 70.3 minutes $(\mathrm{SD}=25.3)$ with range of 46-138 mins.

The stone free rate was $83.3 \%$. In two patients, residual stone was seen, one in isthmus and one in lower calyx. No auxillary procedure was done because when counselled for Extracorporeal lithotripsy, they refused for it and decided to be on follow up. The mean hospital stay was 4.42 days (SD $=1.0$ ) with range of three to six days. Nephrostomy

Table 1. Demographic profile and perioperative variables of the patients

\begin{tabular}{|c|c|}
\hline Total patients & 11 (12 renal units) \\
\hline \multirow{2}{*}{ Gender } & Male - 8 \\
\hline & Female - 3 \\
\hline \multirow{2}{*}{$\begin{array}{l}\text { pelvicalyceal access } \\
(\mathrm{n}, \%)\end{array}$} & $\begin{array}{l}\text { upper pole access - } 10 \text { renal units } \\
(83.3 \%)\end{array}$ \\
\hline & $\begin{array}{l}\text { mid calyceal access }-2 \text { renal units } \\
(17.3 \%)\end{array}$ \\
\hline $\begin{array}{l}\text { Mean stone burden } \\
\left(\mathrm{mm}^{2}\right)\end{array}$ & $\begin{array}{l}385.8(\mathrm{SD}=331.8)(\text { range } 125- \\
1325)\end{array}$ \\
\hline $\begin{array}{l}\text { Stone clearance rate } \\
(\mathrm{n}, \%)\end{array}$ & 83.3 (10 renal units) \\
\hline $\begin{array}{l}\text { Operating time } \\
\text { (minutes) }\end{array}$ & $70.3(\mathrm{SD}=25.3)($ range $46-138)$ \\
\hline Hospital stay (days) & $4.4(\mathrm{SD}=1)($ range $3-6)$ \\
\hline
\end{tabular}


tube drain was removed on the third postoperative day.

The complications noted were of ClavienDindo grade I and II. Fever with chills was seen in one patient. DJ stent was removed and appropriate antibiotic was given. Prolonged urine leak (up to 36 hours after removal of DJ stent) was seen in one patient. One patient needed blood transfusion with hemoglobin dropping to $8.5 \mathrm{gm} \%$. Mean haemoglobin drop was $1.06 \mathrm{gm}(\mathrm{SD}=0.7)$. There were no major complications of bowel and pleural injury. All the punctures made were infracostal.

Comparison of variables of patients with horseshoe kidneys undergoing PCNL is presented in Table 2. It shows that none of the factors are statistically significant.

Table 2. Comparisions of variables of patients with horseshoe kidneys undergoing PCNL

\begin{tabular}{|c|c|c|c|c|}
\hline Variables & & $\begin{array}{l}\text { Stone } \\
\text { free }\end{array}$ & $\begin{array}{l}\text { Residual } \\
\text { stone }\end{array}$ & $\mathbf{p}^{*}$ \\
\hline \multirow{2}{*}{$\begin{array}{l}\text { Age } \\
\text { (years) }\end{array}$} & $21-35$ & 5 & 1 & \multirow{2}{*}{1} \\
\hline & $36-52$ & 4 & 1 & \\
\hline \multirow[t]{2}{*}{ Sex } & male & $\begin{array}{c}8 \text { renal } \\
\text { units (7 } \\
\text { patients) }\end{array}$ & 1 & \multirow[t]{2}{*}{0.49} \\
\hline & female & 2 & 1 & \\
\hline \multirow{4}{*}{$\begin{array}{l}\text { Anatom- } \\
\text { ical stone } \\
\text { location }\end{array}$} & Solitary in pelvis & 5 & 0 & \multirow{4}{*}{0.09} \\
\hline & $\begin{array}{l}\text { Solitary in lower } \\
\text { calyx }\end{array}$ & 2 & 0 & \\
\hline & $\begin{array}{l}\text { Staghorn with } \\
\text { multiple stones in } \\
\text { different calyces }\end{array}$ & 1 & 0 & \\
\hline & $\begin{array}{l}\text { Multiple stones } \\
\text { in lower calyces } \\
\text { including one in } \\
\text { isthmus }\end{array}$ & 2 & 2 & \\
\hline
\end{tabular}

${ }^{*}$ Fisher Exact test

\section{DISCUSSION:}

Various treatment modalities have been used for the stones in horseshoe kidneys. They include extracorporeal shockwave lithotripsy(ESWL), retrograde intrarenal surgery (RIRS), percutaneous nephrolithotomy (PCNL) and laparoscopic/robotic surgery. Many of these treatment options have their own limitations eg. ESWL has very low stone clearance especially in stones larger than two cm.[5] Since horseshoe kidneys are frequently associated with ureteropelvic junction obstruction, laparoscopic or robotic surgery is an option with excellent results.
One can consider laparoscopic or robotic approach in these circumstances for pyelolithotomy along with pyeloplasty.[10,15] Percutaneous surgery is effective, safe and is the most commonly performed treatment modality in patients with stones in the horseshoe kidneys.[16] The atypical anatomical orientation of calyces and pelvis with high lateral insertion of the ureter makes the spontaneous passage of fragments after lithotripsy less likely. The reported stone clearance rate in horseshoe kidney in ESWL is 28-78\%.[17] Overall the stone burden in anomalous kidneys is usually higher than in normal kidneys. [18] Wickham and Kellet in 1981 and Clayman in 1983 first reported percutaneous extraction of stones in horseshoe kidneys. Since then it has been widely accepted as the standard treatment for stones greater than two cm or when ESWL has failed.[10]

During percutaneous access in horseshoe kidneys, one should consider that there are two main factors different from the normal renal anatomy eg the blood supply and the orientation of the pelvicalyceal system. The blood supply to horseshoe kidneys except to the isthmus is on its ventromedial aspect but the access is made on the dorsolateral side. The blood supply to isthmus is protected by spine and are thus away from the access tract to the pelvicalyceal system. Therefore the risk of bleeding during PCNL is not higher than in normal kidney.[19]

In normal kidneys, the percutaneous access to the upper pole calyx often requires supracostal puncture with increased risk of pleural injury. However in horseshoe kidneys due to the inferior displacement of kidneys away from the pleura, upper pole access is relatively safe. Moreover, the nephroscope lies in alignment with the long axis of the kidney making easy access to the upper calyces, renal pelvis, lower calyces, pelviureteric junction and upper proximal ureter minimising the nephroscope torque on renal tissue.[20,21] In our study, we had upper pole calyceal access in 10 renal units and mid calyceal access in two renal units without any pleural and bowel injury. Though CT scan abdomen was recommended by Al-Otaibi in every case before surgery due to abnormal relationship with other viscera, we had done CT abdomen in only six cases (seven renal units) from 2015. There was no difficulty in getting percutaneous access to the pelvicalyceal system before 2015.[22]

Commonest presentation of patients in our study was flank pain $(54.5 \%)$ followed by haematuria (27.2\%) and dysuria (18.4\%) comparable to the study 
by Symons SJ et al.[21] The mean stone burden was $385 \mathrm{~mm}^{2}(\mathrm{SD}=331.8$, range $125-1325)$ and the mean operating time from puncture to the completion of the procedure was 70.3 minutes $(\mathrm{SD}=25.3$, range 46-138 )

The stone clearance rate in our study was 83.33\% at six weeks. In two patients (two renal units), when counselled for auxiliary procedure ,they chose to be on follow up later on. Therefore no auxiliary procedure was done. The stone free rate regarding the age and sex of the patients was not statistically significant. The anatomical location of the stone is considered to affect the stone free rate though the statistical value was not significant in our study probably due to small sample size. The residual stone in our study was in lower calyx and in the isthmus. Most of the series of PCNL in horseshoe kidneys report the stone free rate from $72 \%-91 \%$. $[23,24]$ In the study by Ercan Bas et al., the stone free rate was $86 \%$.[25] Though the complications are less affected by the abnormal anatomy of horseshoe kidneys, stone burden, demographic and operative parameters, the stone complexity, location and multiplicity are reported to determine the stone free status.[26] Similarly the stone free rate in the series of 64 renal units (45 patients) by Blackburne AT et al. was $81.1 \%$ with the complications of Clavien grade II in three patients(4.68\%).[27] Different studies of PCNL in horseshoe kidneys and their results is shown is Table 3.

The complications encountered in our study were of Clavien-Dindo grade I and II and were seen in three patients (27.27\%). One patient got fever with chills and was managed by appropriate antibiotics and DJ stent was removed. There was prolonged urine leak up to 36 hours after removal of nephrostomy tube in one patient. One patient needed blood transfusion.The mean drop of haemoglobin was $1.06 \mathrm{gm} \%(\mathrm{SD}=0.76)$. All the punctures were made infracostal without pleural and bowel injury.
Most of the series of PCNL in horseshoe kidneys have reported the complication rate from $0-16.7 \%$. $[23,17]$ In the series of 21 patients by Etemadian $\mathrm{M}$ et al. and of seven patients by Ercan Bas et al, the complication rate was $14 \%$ and $28.5 \%$ respectively. $[24,25]$ Similarly, Salahhedin et al. reported the complication rate to be $47.5 \%$ with the Clavien grade IIIa being only $8.7 \%$.[28 ]

\section{Limitations:}

Extracorporeal shockwave lithotripsy (ESWL) and Retrograde intrarenal surgery(RIRS) could be good options for smaller single stone in patients with horseshoe kidney. We do not have these armamentarium in our institute at present. Moreover, the stone free rate in horseshoe kidney is believed to increase with the flexible nephroscope especially with the stones in the isthmus and lower calyx which are sometimes inaccessible with rigid nephroscope. Unfortunately flexible nephroscope is also not available in our institute.

\section{CONCLUSION:}

Percutaneous nephrolithotomy is safe, feasible and is an effective method in the management of stones in the horseshoe kidneys with excellent stone free rate and minimal complications. It does not carry the increased risk than reported for the normal kidneys. However it requires careful preoperative planning and the operating surgeon needs to be alert for all possible intra and postoperative complications.

\section{ADDITIONAL INFO:}

Competing interests: None declared

Financial disclosure: No funds were available

\section{Acknowledgement:}

- Entire OT staff family, KMCTH.

- Dr Naresh Manandhar

Table 3: Different series of PCNL in horseshoe kidneys and their results

\begin{tabular}{lccccc}
\hline Series & $\mathbf{N}$ & $\begin{array}{c}\text { upper pole access } \\
\mathbf{( \% )}\end{array}$ & $\begin{array}{c}\text { Complications } \\
\mathbf{( \% )}\end{array}$ & $\begin{array}{c}\text { stone free rate } \\
\mathbf{( \% )}\end{array}$ & $\begin{array}{c}\text { auxiliary procedure } \\
\mathbf{( \% )}\end{array}$ \\
\hline Stephanie et al [21] & 47 & 48 & 23 & 88 & 34 \\
Lingermann JE et al [26] & 17 & 81 & 29 & 84.6 & 73 \\
Al-Otaibi and Hosking [22] & 12 & 75 & 42 & 75 & 71.4 \\
Etemadian et al [24] & 21 & 66.64 & 9.52 & 83.3 & not available \\
Our study & $\begin{array}{c}11 \text { (12 renal } \\
\text { units) }\end{array}$ & 83.3 & 27.27 & & 0 \\
\hline
\end{tabular}




\section{REFERENCES:}

1. Baur BS. Anomalies of form and fusion, crossed renal ectopia with and without fusion. Alan J, editor Wein: Campbell-Walsh Urology Book 9th edition. Philadelphia: WB Saunders; 2007,p 3269-304. https://doi. org/10.4103/0971-9261-107006

2. Prasad DVS R, Srinivas S. Problems of fused kidneys- Our observations. IAIM. 2016;3(9):182-88. http://oaji.net/pdf. html?n=2017/1398-1489651747.pdf

3. Glenn JF. Analysis of 51 patients with horseshoe kidney.N Engl J Med. 1959; 261:684. https://doi.org/10.1056/NEJM 195910012611402 PMID: 13828436

4. Shah HU, Ojili V. Multimodality imaging spectrum of complications of horseshoe kidney. Indian J Radiol. Imaging.2017;27(2):133-40. https://doi,org/10.4103/ijri. IJRI_298_16

5. Raj GV, Auge BK, Weizer AZ, Denstedt JD, Watterson JD, Beiko DT et al. Percutaneous management of calculi within horseshoe kidneys. J Urol.2003; 170(1):48-51. https:// doi. org/ 10.1097/01.ju. 0000067620.2d PMID: 12796642

6. Bansal P, Bansal N, Sehgal A, Singla S. Flexible ureteroscopy for lower calyceal stones in a horseshoe kidney- Is it the new treatment of choice? African Journal of Urology. 2016;22:199-201. https://doi.org/10.1016/j. afu.2016.01.007

7. Pawar AS, Thongprayoon C, Cheungpasitporn W, Sakhuja A, Mao MA, Erickson SB. Incidence and characteristics of kidney stones in patients with horseshoe kidneys: A systematic review and meta-analysis. Urol. Ann. 2018; 10(1):87-93. https://doi.org/10.4103/UA-UA_76_17

8. Skolarikos A, Binbay M, Bisas A, Sari E, Bourdoumis A, Tafekli A et al. Percutaneous nephrolithotomy in horseshoe kidneys: Factors affecting the stone free rate. J Urology.2011;186:1894-98. https://doi.org/10.14260/ jemds/2014/2540

9. Ozden E, Bilen CY, Mercimek MN, Tan B, Sarikaya S, Sahin A et al. Horseshoe kidney: does it really have any negative impact on the surgical outcomes of percutaneous nephrolithotomy? Urology. 2010 ;84:1219-25. https://doi. org/10.1016/ J Urology 2009.08.054 PMID: 19931900

10. Osther PJ, Rizvi H, Liatsikos SE. Percutaneous nephrolithotomy among patient with renal anomalies: patient characteristics and outcomes: a Subgroup analysis of the CROES Global PCNL study. J Endourol. 2011;25(10):1627-32. end.2011.0146 PMID: 21790475

11. Lanz AG, Honey RJD. Lumbar plexopathy as a complication of Percutaneous nephrolithotomy in horseshoe kidneys. CUAJ. 2015;9(1-2):78-80. https://doi.org/10.5489/ cuaj.2468. PMID: 257377674

12. Turk C, Knoll T, Petric A, Sarica K, Skolarikos A, Straub $\mathrm{M}$ et al. Guidelines on urolithiasis. European Association of Urology. 2016. https://uroweb.org/wp-content/uploads/ EAU-Guidelines-Urolithiasis-2016

13. Gaurav P, Sinha RJ, Jhanwar A, Bansal A, Singh V. Outcome of Percutaneous nephrolithotomy in anomalous kidneys. Is it different? Urol. Ann.2017;9(1):23-26. https:// doi.org/10.4103/0974-7796.198836

14. Yohannes $\mathrm{p}$, Smith AD. The endourological management of complications associated with horseshoe kidney. J Urol.2002;168(1):5-8 Review. PMID: 12050480

15. Olcucuoglu E, Camtosun A, Bicer S, Bayraktar AM. Laparoscopic pyelolithotomy in a horseshoe kidney. Turk J Urol. 2014;40(4):240-44. https://doi.org/10.5152/fud 2014.73604 PMID: 26328185
16. Sohail N, Albodour A, Abderlrahman KM, Bhatti KH. Supine percutaneous nephrolithotomy in horseshoe kidneys. Journal of Taibah University Medical Sciences. 2017;12(3):261-64. https://doi.org10.1016/j.jtumed 2016.12005

17. Viola D, Anagnotsu T, Thompson TJ, Smith G, Moussa SA, Tolley DA. Sixteen years of experience with stone management in horseshoe kidneys. Urol Int. 2007;78(3):214-18.

18. Braticevici B, Salahedin Y, Ambert V, Petca RC, Diaconescu $\mathrm{D}$, Rascu $\mathrm{S}$ et al. Complications of percutaneous nephrolithotomy classified by the modified clavien grading system-a single center experience over 18 months. Revista Romana De Urologie.2014;13(1):18-22.https:// pdfs.semanticscholar.org/dfb3/b40dde697

19. Janetschek G, Kunzel KH. Percutaneous nephrolithotomy in horseshoe kidneys. Applied anatomy and clinical experience. BJU Int.1988;62:117-22. https://doi. org/10.1111/j.1464-410X.1988

20. Miller NL, Matlaga BR, Handa SE, Munch LC, Lingerman JE. The presence of horseshoe kidney does not affect the outcome of percutaneous nephrolithotomy. J Endourol.2008;22(6)1219-25. https://doi.org/10.1089/ end.2008.0051 PMID: 18484885

21. Symons SJ, ramachandran A, Kurien A, Baiysha R, Desai MR. Urolithiasis in the horseshoe kidney: a single centre experience. BJU Int.2008;102(11)1676-80.https://doi. org/10.1111/ J.1464-410x2008.07987 PMID: 18782315

22. Al-Otaibi K, Hosking DH. Percutaneous stone removal in horseshoe kidneys. J Urol. 1999;162:674-77. PMID: 10458339

23. Tepelar A, Sehgal PD, Akman T, Unsal A, Ozyuvali E, Armagan A et al. Factors affecting outcomes of percutaneous nephrolithotomy in horseshoe kidneys. Urology. 2014;84(6):1290-94. https://doi.org/10,1016/ J. Urology 2014.08.008 PMID: 25304208

24. Etemadian M, Maghsoudi R, Abdollahpour V, Amjadi M.Percutaneous nephrolithotomy in horseshoe kidneys. Our five year experience. Endourology and stone disease. 2013; 10(2):856-60. https://pdfs,semantics scholar. org/1d32/83c PMID: 23801467

25. Bas E, Altok M, Umul M, Gunes M. Percutaneous nephrolithotomy in horseshoe kidneys: Our First Experience. Journal of urological Surgery.2015;1:17-21. https://doi.org/10.4274/ Jus.236

26. Lingerman JE, Saw KC. Percutaneous operative procedures in horseshoe kidneys. The Journal of Urology.1999; 161:371. https://doi.org/10.4274/ jus.236

27. Blackburne AT, Rivera ME, Gettman MT, Patterson DE, Krambeck AE. Endoscopic Management of Urolithiasis in horseshoe kidney. Urology. 2016; 90:45-49. https://doi. org/10.1016/j.Urology 2015.12.042 PMID: 26772644

28. Salahhedin Y, Petca RC, Predoiu G, Danau RA,Petca A, Mastalier B, Badiu DC et al. Percutaneous nephrolithotomy for the treatment of urolithiasis in horseshoe kidneys. Proc.Rom. Acad. Series B.2017;19(2):87-92. www.acad.ro/ sectii2002/proceedingsChemistry/doc2017-2/art04.pdf 